\title{
High Resolution Geochemical Mapping of Fossil Coccospheres of Coccolithophores in Organic Chalks using Energy Dispersive Spectroscopy and Back Scatter Electrons
}

\author{
David Jacobi ${ }^{1}$, John Longo ${ }^{2}$, Fabian Duque ${ }^{3}$ and Felix Oyarzabal ${ }^{4}$
}

${ }^{1}$ Aramco Americas, Houston Research Center, Houston, Texas, Houston, Texas, United States, ${ }^{2}$ Chemistry in Action, Houston, Texas, United States, ${ }^{3}$ Saudi Arabian Oil Co., Dhahran 31311 Kingdom of Saudi Arabia, Saudi Arabia, ${ }^{4}$ Saudi Arabian Oil Co., Dhahran, Saudi Arabia

Innovative software, formerly designed to map and quantify both the mineralogy and organic matter of two-dimensional (2D) scanning electron images of source rocks [1], using energy dispersive spectroscopy (EDS) and back scatter electrons (BSE), has recently been used to map the mineralogy and chemistry of preserved coccospheres of ancient coccolithophores in organic chalks. Mineral maps computed from EDS and BSE elemental maps show cross sections of intact fossilized carbonate coccospheres that contain organic matter with high sulfur content, defining the potential cellular diameter of the former organism. The detection and mapping of organosulfur within the coccosphere suggests the ancient unicellular organism may have biosynthesized sulfur compounds like that reported to occur in modern species, an element which is currently thought to influence the global climate.

The coccolithophore is a species of algal phytoplankton that has existed since the Triassic period through to the modern era [2][3]. Its survival has depended upon the use of euphotic marine surface waters to develop a carbonate exoskeleton composed of interlocking distal and proximal radial disks called "coccoliths" that form a "coccosphere" surrounding the organism [2][3](Fig. 1 a,b, and c). The inorganic precipitation of calcium carbonate that creates these coccoliths also produces carbon dioxide $(\mathrm{CO} 2)$ within the cellular structure of the algae which is then used by the organism to photosynthesize additional organic matter [2][3], according to the following process:

$$
\begin{aligned}
& \mathrm{Ca} 2++2 \mathrm{HCO} 3-\rightarrow \mathrm{CaCO} 3+\mathrm{CO} 2 \text { (gas) }+2 \mathrm{H}+ \\
& \mathrm{CO} 2 \text { (gas) }+\mathrm{H} 2 \mathrm{O} \rightarrow \mathrm{CH} 2 \mathrm{O} \text { (biomass) }+\mathrm{O} 2
\end{aligned}
$$

As a result, the organism's metabolism exports a large budget of carbon to the ocean and controls the $\mathrm{pH}$ of the water [4].

Fossil evidence of intact coccospheres of the ancient organism are very rare and seldom observed in organic chalks. However, the morphology of a coccosphere and the organism's potential cell diameter are both easily identified in the backscatter image and the mineral map of the organic chalk in figure 2a and $2 \mathrm{~b}$. The nanoscale resolution of the mineral map produced by the software helps distinguish boundaries between the carbon associated with inorganic calcite (light blue) versus that defining the organic carbon (black) associated with the chalk and coccospheres. It also aids in defining the cell diameters of the coccospheres, and in revealing the remaining composition of the other mineral phases associated with the contrasting intensities recorded across the BSE image, the lowest of which could have been misinterpreted as porosity instead of organic matter without the results of the mineral map.

Apart from the coccosphere observed in the BSE and mineral map, usually the only visible remnants of a coccolithophores existence in the fossil record are from the coccoliths observed composing chalks. The morphology and size of these are depicted in figure 1c and identified in the back-scatter electron image of figure $2 \mathrm{a}$, both as parts of the aperture and distal and proximal shields of the coccolith. 
Fossil coccolith biometry (Fig. 1c)., including size, length, and the degree of circularity has been used to empirically estimate the size of coccospheres when they are not preserved to determine the cell diameter of the organism[2]. This is calculated based on similar biometric criteria measured from coccoliths from modern coccospheres. Thus, the size of an intact coccosphere compared to a coccolith seen in the map and BSE image of $2 \mathrm{a}$ and $2 \mathrm{~b}$ can provide calibration for this method to get a better estimate of the cell diameter to improve understanding about the organism's physiology during different geologic periods. However, there may also be yet another reason for the frequent occurrence of coccoliths as opposed to coccospheres in the fossil record that is related to the sulfur content found composing the organic matter in chalks.

The sulfur biogeochemistry of organic matter in chalks suggests ancient coccolithophores may have had a unique metabolic legacy that has been inherited by the modern species which chemically assimilates sulfur into their unicellular structure as dimethylsulfoniopropionate [4]. This biosynthesis is responsible for periodic releases of dimethyl sulfide by the organism into the atmosphere during periods of heightened algal bloom activity which has implications for cooling the global climate by increasing the earths albedo [4][5]. The periodic release of this biogenic gas accompanies the shedding of coccoliths around the organism. This phenomenon has been observed visually by satellite and measured by trace gas analysis on a global scale [4]. The periodic occurrence of this process as recorded in modern times may also explain the often-found abundance of coccoliths composing ancient chalks instead of coccospheres.

Some evidence of the ancient coccolithophores potential influence on earlier climates may be seen from the images and mineral maps of the intact coccosphere. The organic matter contained therein contains a significant amount of organosulfur (Fig 2c and 2d) which indicates the ancient organism might have also assimilated this compound into its cellular biomass. The organosulfur was determined using the iron elemental map to subtract a sulfur amount associated with that of the pyrite computed from the mineral map, the residual of which is then used to develop a carbon map of the organosulfur present in the rock (Fig. 2c and 2d)[6]. The presence of organosulfur within the intact coccosphere may indicate the ancient coccolithophore species could have had climatic influence during certain geologic periods that would enhance their chance of survival in nutrient poor surface waters, not unlike their modern analogues. 


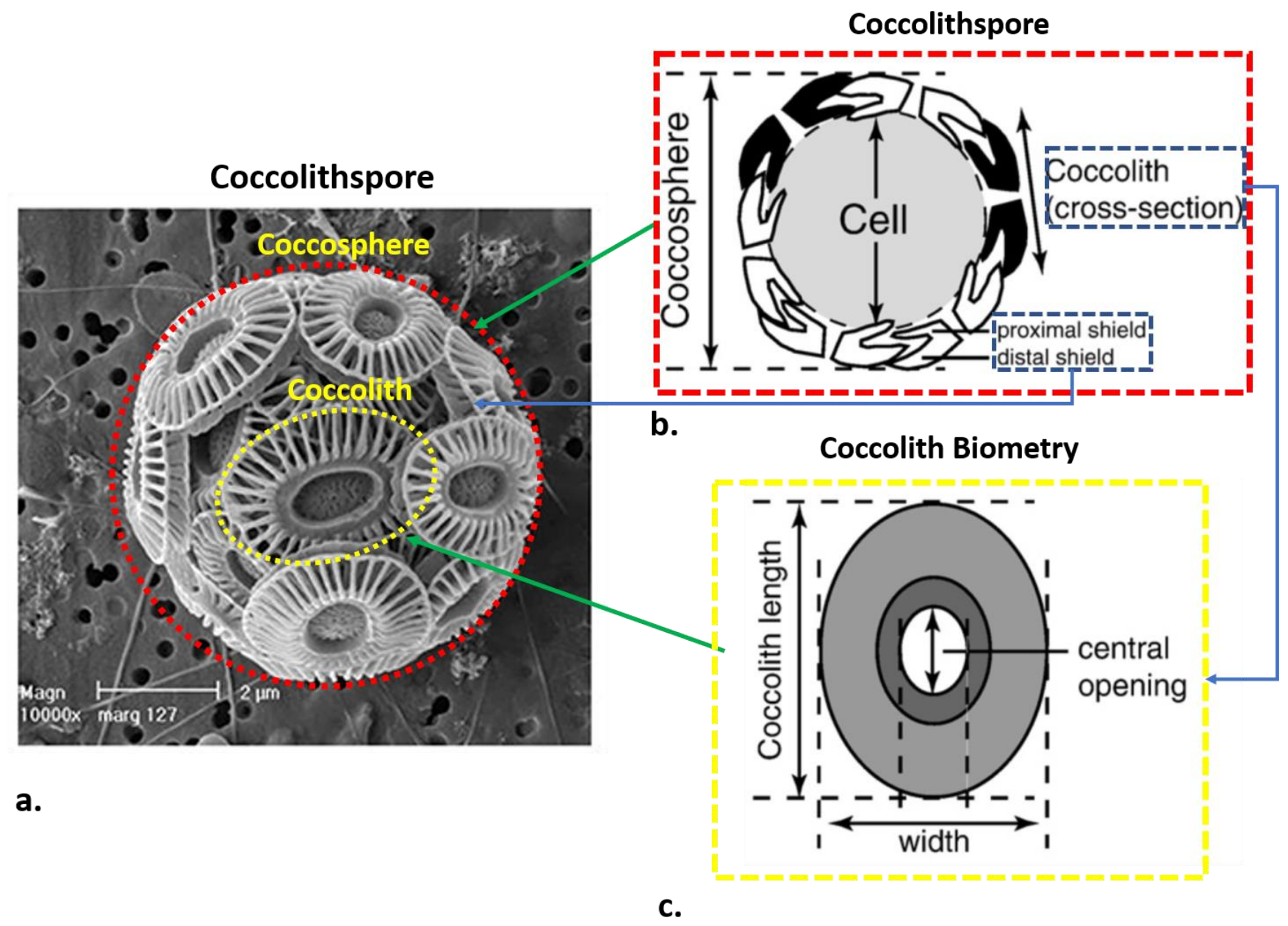

Figure 1. (a.) Diagram showing image of modern coccolithophore and (b.) a schematic of a fossilized coccospheres morphology with cell diameter (c.) and the coccoliths potential biometric components. a. Modified from Neukermans and Fournier, 2018; b. and c. modified from Henderiks, 2008 


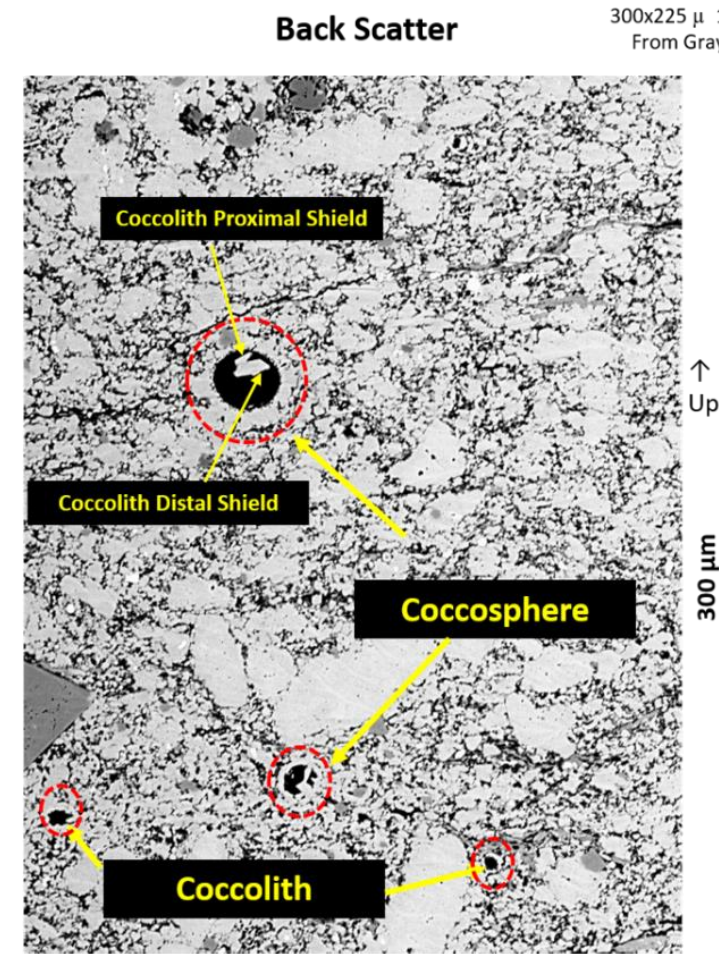

a.

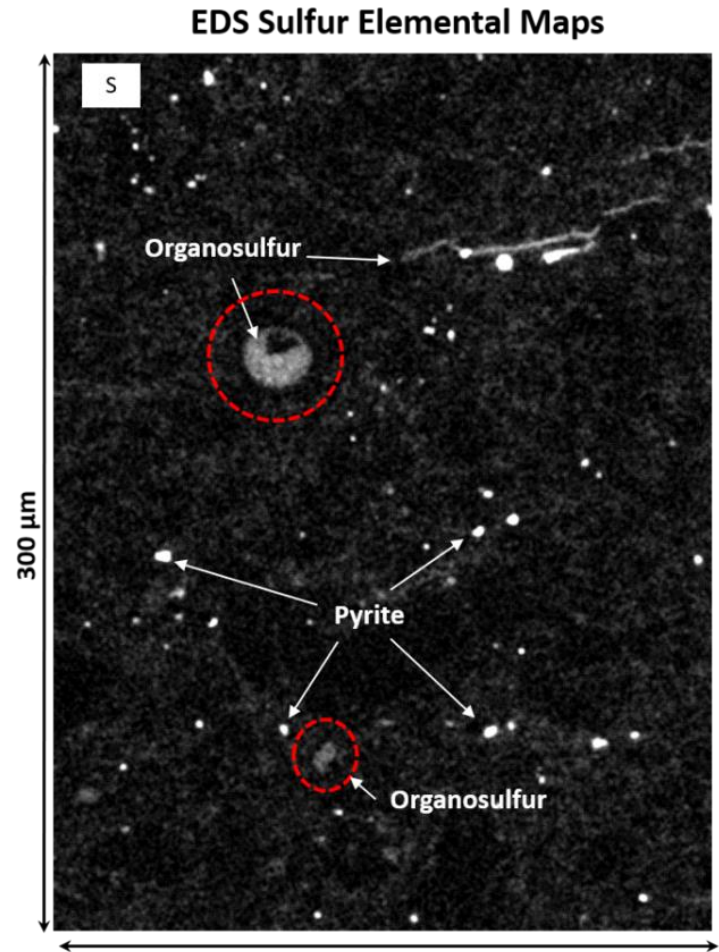

c.

Subtracting the pyrite sulfur using the iron map

produces a map of organic sulfur that compares well with the carbon map

b.

d.

\section{Mineral Map}

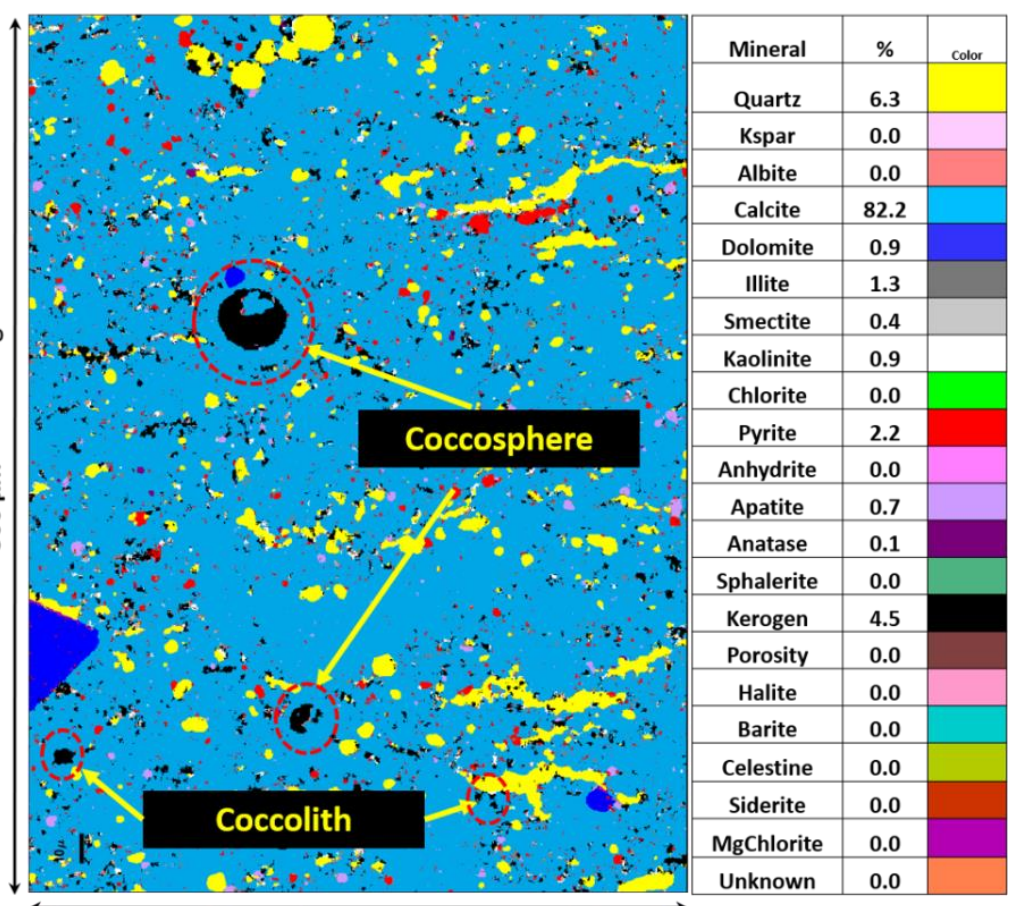

$225 \mu \mathrm{m}$

\section{Sulfur Map of the Organic}

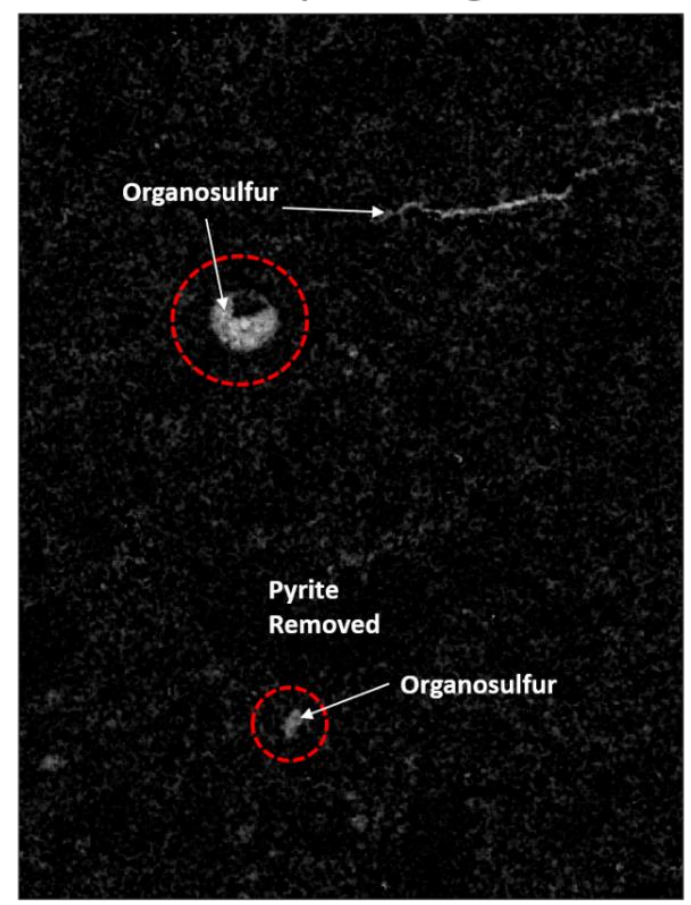

$\operatorname{Organic} \mathrm{S}=\mathrm{S}-\mathrm{Fe}(\mathrm{S})$

Figure 2. Figure 2. (a) Backscatter electron image of chalk showing the morphology of intact coccosphere and remnant coccoliths, normally the only evidence of coccolithophores in chalks (b) Mineral map of the 
mineralogy and organic matter of the chalk. (c) EDS sulfur elemental map from chalk. (d) Computed organosulfur map based on the subtraction of the removal of pyrite sulfur using the iron elemental map.

\section{References}

[1] Jacobi D., Sun Q., Longo J., Brothers J. and Kone J., 2019. Innovative Mapping of Mineral and Organic Matter of Source Rocks at the Nanometer Scale Using Back Scatter Electron and Energy Dispersive Spectroscopy. Microscopy and Microanalysis 25, S2. 2422-2423

[2] Henderiks J., 2008 Coccolithophores size rules - Reconstructing ancient cell geometry and cellular calcite quota from fossil coccoliths. Marine Micropalentology 67, 143-154.

[3] Halder K., 2016. The Magical World of Coccolithophores. https://joidesresolution.org/the-magical-worldof-coccolithophores/

[4] Malin G. and Steinke M., 2004. Dimethyl sulfide production: what is the contribution of the coccolithophores? Thierstein H.R. et al. eds. in Coccolithophores, Springer-Verlag, Berlin Heidelberg, 128163.

[5]Neukermans G. and Fournier G., 2018. "Optical Modeling of Spectral Backscattering and Remote Sensing Reflectance from Emiliania huxleyi blooms”. Front Mar. Sci. Methods, p 1-20.

[6]Jacobi D. and Longo J.M., 2020. Non-destructive Mapping of Organosulfur of Source Rocks Using Energy Dispersive Spectroscopy and Back Scatter Electron. Microscopy and Microanalysis. 26, 2, 3212-3214 